\title{
Lipid Content in Pig Blastocysts Cultured in the Presence or Absence of Protein and Vitamin E or Phenazine Ethosulfate*
}

\author{
Marek RoMEK, Barbara GAJDA, Ewa KRZYSZTOFOwiCZ, Mariusz KĘPCZYŃSKI, \\ and Zdzisław SMORĄG
}

Accepted October 5, 2010

\begin{abstract}
Romek M., Gajda B., KRZYSZTOfowiCZ E., KęPCZYŃSki M., SMORĄG Z. 2011. Lipid content in pig blastocysts cultured in presence or absence of protein and vitamin E or phenazine ethosulfate. Folia biologica (Kraków) 59: 45-52.

In the present study, total lipid content and content of triglycerides, phospholipids and cholesterol were determined in pig blastocysts cultured in medium without protein, supplemented with bovine serum albumin (BSA), with fetal calf serum (FCS), vitamin E or phenazine ethosulfate (PES). In comparison to blastocysts cultured in NCSU-23 with BSA, we observed a decrease of the total lipid content in PES-treated embryos. Triglyceride content in FCS-, vitamin E- and PES-treated embryos as well as in blastocysts cultured without protein was $81.9 \%, 70.2 \%, 57.2 \%$ and $74.8 \%$ of that found in the blastocysts cultured in NCSU-23 with BSA, respectively. Nevertheless the content of phospholipids remained unchanged. This decrease of triglyceride content in the porcine blastocyst after in vitro culture may be explained by altered lipid metabolism in embryos.

Key words: Pig embryo, lipid, vitamin E, PES, FCS, BSA.

Marek ROMEK, Ewa KRZYSZTOFOWICZ, Department of Cytology and Histology, Institute of Zoology, Jagiellonian University, R. Ingardena 6, 30-060 Kraków, Poland.

E-mail:marek.romek@uj.edu.pl

Barbara GAJDA, Zdzislaw SMORĄG, Department of Animal Reproduction Biotechnology, National Research Institute of Animal Production, 32-083 Kraków-Balice, Poland.

Mariusz KĘPCZYŃSKI, Faculty of Chemistry, Jagiellonian University, R. Ingardena 3,

30-060 Kraków, Poland.
\end{abstract}

Pig embryos have a very low survival rate after cryopreservation due to their extreme, speciesspecific sensitivity to cooling below $15^{\circ} \mathrm{C}$ (DOBRINSKY 2002). This chilling susceptibility appears to depend on the developmental stage of the embryo (DOBRINSKY 2002), so the expanded blastocyst exhibits higher cryotolerance than the less advanced stages, but it is low in comparison to other mammalian species (GAJDA \& SMORAG 2000). On the other hand porcine embryos have a very high total lipid content which decreases after morulae compaction (MCEVOY et al. 2000; ROMEK et al. 2009). Therefore, susceptibility to cryopreservation correlates with lipid content because physical changes of lipids in freezing temperatures cause cellular cryodisruption (PEREIRA \& MARQUES 2008) and embryos with a high lipid level are more susceptible to oxidative damage (MCEVOY et al. 2001) and to injury of cytoplasmic lipid droplets (VAJTA \& NAGY 2006). In fact, im- provement of pig embryo survival after freezing can be achieved by mechanical removal of cytoplasmic lipid droplets (NAGASHIMA et al. 1994; YONEDA et al. 2004). Another possible strategy may be developing a porcine embryo culture system to obtain porcine blastocysts with reduced level of lipids.

North Carolina State University (NCSU)-23 medium is known to be one of the most successful for porcine embryo culture (RATH et al. 1995). This medium is usually supplemented with bovine serum albumin (BSA) or fetal calf serum (FCS). In some previous reports, the culture of early porcine embryos with FCS was detrimental to blastocyst development in vitro, significantly reduced the formation of hatched blastocysts (DOBRINSKY et al. 1996; GAJDA et al. 2008) and caused accumulation of lipids in bovine embryos (BARCELO-FIMBRES \& SEIDEL 2007). Alternatively, it was shown that NCSU-23 medium supplemented with BSA 
significantly improved porcine embryo development and the quality of the resulting blastocyst (GAJDA et al. 2008). Beneficial effects of supplementing the culture medium with vitamin $\mathrm{E}(\alpha-\mathrm{t}$ ocopherol), the predominant lipid-soluble antioxidant, were also described (GAJDA et al. 2008; TSUJII et al. 2002). This antioxidant increases the survival rates and quality of porcine blastocysts by protecting cells from oxygen radical damage and suppresses peroxidation of membrane lipids. In addition, it has a significant impact on glucose incorporation and metabolism at the blastocyst stage (TSUJII et al. 2002). It was demonstrated previously that bovine embryos cultured in a medium with phenazine ethosulphate (PES) (DE LA TORRE-SANCHEZ et al. 2006; BARCELO-FIMBRES \& SEIDEL 2007) accumulated less lipids and had an apparently more normal distribution of lipid deposits due to the stimulation of the pentose phosphate pathway rate by PES (PALASZ et al. 2008). Bovine embryos cultured with PES also showed an increased ability to survive cryopreservation (SEIDEL 2006). Finally, it is possible to improve the quality of cultured bovine (DE LA TORRE-SANCHEZ et al. 2006; PALASZ et al. 2006) and porcine embryos (GAJDA et al. 2008) using different chemicals to regulate their metabolism.

It was previously pointed out that Nile red (NR) could be applied to measure the total lipid content in single mammalian oocytes and embryos (LEROY et al. 2005; GENICOT et al. 2005). Furthermore, NR is a solvatochromic probe with fluorescent emission spectrum sensitive to the polarity of its environment (MUKHERJEE et al. 2007; KĘPCZYŃSKI et al. 2008). In embryos, especially in the intracellular lipid droplets, such an environment consists of different types of lipids, mainly triglycerides, phospholipids and cholesterol (MCEVOY et al. 2000) which exhibit different degrees of polarity. Thus, NR staining followed by decomposition of the emitted spectrum yields quantitative information about the content of the main types of lipids in embryos.

Taking into account that BSA, FCS, PES and vitamin E may regulate the rate of different processes in the embryo during in vitro culture, an important question arises whether supplementation of the culture medium with or without proteins (FCS or BSA), metabolic regulators or antioxidants will decrease the total lipid content and the content of the main types of lipids, i.e. triglycerides, phospholipids and cholesterol in cultured porcine blastocysts.

\section{Material and Methods}

All chemicals were supplied by Sigma-Aldrich Co. (St. Louis, MO, USA) unless otherwise indi- cated. Experimental procedures used in this study were approved by the Local Ethics Committee at Jagiellonian University, Kraków, Poland.

\section{Embryo recovery and culture}

Porcine embryos were collected from mature, six-month-old gilts (Polish Landrace) with body weight ranging from 90 to $110 \mathrm{~kg}$. The gilts were superovulated by intramuscular injection of 1500 IU of PMSG (Serogonadotropin, Biowet, Poland), followed $96 \mathrm{~h}$ later by $1000 \mathrm{IU}$ of hCG, (Biogonadyl, Biowet, Poland) i.m., and inseminated twice: 12 and $24 \mathrm{~h}$ after hCG treatment. The embryos were recovered by flushing oviducts on day 1 after insemination with phosphate buffered saline (PBS) at about $30^{\circ} \mathrm{C}$. Embryos at the zygote stage were then cultured in NCSU-23 medium supplemented with $4 \mathrm{mg} / \mathrm{ml}$ bovine serum albumin (BSA group) or $10 \%$ fetal calf serum (FCS group) or $0.05 \mu \mathrm{M}$ phenazine ethosulfate (PES group) or $25 \mu \mathrm{M}$ vitamin $\mathrm{E}$ (VE group) or without protein (control group -C). The culture was performed at $39^{\circ} \mathrm{C}$, with $5 \% \mathrm{CO}_{2}$ in air, for 96 to $120 \mathrm{~h}$ up to the expanded blastocyst stage.

\section{Blastocyst processing}

Nile Red (NR, Molecular Probes, Inc., Eugene, OR, USA) was used to label lipid droplets. All processing stages were performed at room temperature. Blastocysts were washed in PBS, incubated with $0.1 \%(\mathrm{w} / \mathrm{v})$ pronase to remove zona pellucida, washed in PBS again, fixed with $4 \%$ paraformaldehyde in PBS for $3 \mathrm{~h}$, washed three times for $15 \mathrm{~min}$ in PBS and stained with $10 \mu \mathrm{g} / \mathrm{ml}$ NR in PBS for $3 \mathrm{~h}$ in dark. Subsequently embryos were rinsed twice in PBS to remove excess dye, immersed in small PBS droplets placed on glass coverslips and sealed with a second glass coverslip. To prevent embryo-destroying we formed vaseline ring around PBS droplets. In the each group ten blastocysts were evaluated.

\section{Image acquisition}

Blastocysts were analysed on a LSM 510 META confocal system and a Zeiss Axiovert 200M inverted microscope (Carl Zeiss GmbH, Jena, Germany) equipped with a Plan- Apochromat $20 \times(0.8$ NA) lens. We used a $514 \mathrm{~nm}$ Argon/2 laser line for NR excitation. The whole volume of each blastocyst was sampled by a set of adjacent optical sections taken at intervals of $5 \mu \mathrm{m}$ ("z-stack"). Each optical section in the z-stacks consisted of $22 \mathrm{im}$ ages taken at different emission wavelengths ranging from 518 to $754 \mathrm{~nm}$ at intervals of $10.4 \mathrm{~nm}$ 
("lambda stack"). This analysis, named the Lambda Mode scanning procedure, allows acquiring NR emission spectra emitted from optical sections of blastocysts. For each optical section, the emission spectrum emitted from the region of interest (ROI) containing whole blastocyst cross-sections was measured using LSM 5 software (Carl Zeiss GmbH, Jena, Germany). Then background emission spectra, emitted from ROI located outside of the embryos cross-sections were subtracted. In the same way we acquired emission spectra of the three standards: triglyceride mixtures (cat. no. 17811), phospholipid mixture for HPLC (cat. no. P3817) and Liquick Cor-CHOL mini: 2-standard (Cormay Co., Lublin, Poland, cat. no. 2-212) containing cholesterol. These standards were stained with $10 \mu \mathrm{g} / \mathrm{ml}$ NR solution for $3 \mathrm{~h}$ at room temperature in the dark and then analysed using confocal microscopy.

\section{Data analysis}

We evaluated four parameters for each individual embryo in all groups: the total content of lipids - TF, as well as the content of triglycerides $\mathrm{TF}($ tri), phospholipids - TF(ph) and cholesterol $\mathrm{TF}$ (chol). To evaluate the total content of lipids for each individual blastocyst we measured the amount of fluorescence (ID) emitted from each optical section in the z-stack as the area under the emission spectra. Sum of ID calculated for all optical sections of each individual blastocyst equals the total amount of fluorescence emitted from the blastocyst and is proportional to the total content of lipids (GENICOT et al. 2005). To compensate the effect of losing emitted fluorescence in the z-stack when imaging further into deeper regions of embryos (where excitation and detection efficiency decreases), we employed the Interpolate function of LSM 5 software, Version 4.0 (Carl Zeiss $\mathrm{GmbH}$, Jena, Germany). For statistical analysis we used normalised data $|\mathrm{TF}|$ :

$$
|T F|=\frac{T F}{\overline{T F(B S A)}}
$$

where $\overline{T F(B S A)}$ is mean TF calculated for BSA group. The total lipid content of blastocysts was compared using a one-way ANOVA with a post hoc Tukey test.

In order to evaluate the total content of triglycerides, phospholipids and cholesterol in the individual blastocysts from different groups, we calculated the mean emission spectrum for each blastocyst from the spectra of all optical sections in the embryo and then this mean spectrum was normalised by the area under them. Using principal component analysis (PCA) (TEIXEIRA et al. 2009), we obtained the number of principal components, i.e. number of principal or component spectra in the mean, experimental spectra of blastocysts. The next step was decomposition of the experimental emission spectra into principal spectra using a multivariate curve resolution-alternating least squares (MCR-ALS) (TAULER 1995). This method allows receiving the pure spectrum of each principal component $-S_{P}(j)$ and its multiplying factor $M^{i}(j)$, i.e. the pure concentration profiles proportional to the percentage content of the different types of lipid in the $i$-th blastocyst, according to the following equation:

$$
\text { (2) } S_{\text {exp }}^{i}=\sum_{j} M F^{\mathrm{i}}(j) \cdot S p(j)+E
$$

where $S_{P}(j)$ and $M F^{i}(j)$ are the principal spectrum and multiplying factor of component $j$ retrieved in $i$-th blastocyst and $\mathrm{E}$ is an error matrix. The best fit was expressed as percent variance (PVC) captured by the PCA model. All calculations were performed in a two-step procedure using Matlab 7.6 software (The MathWorks, Inc., Natick, MA). Values of $\mathrm{MF}^{i}(\mathrm{j})$ were analysed with three-dimensional ANOVA and a post hoc Tukey test using Statistica version 5.0 software (StatSoft Inc., Tulsa, OK, USA). To identify principal components we compared each of the threecomponent spectrum with the spectrum measured for appropriate standard of triglyceride mixtures, phospholipid mixture or cholesterol. The coefficient of determination $R^{2}$ is a measure of the deviation of the component spectrum from the experimental data of the lipid standards and is calculated by the formula (KURGANOV et al. 2001):

$$
\text { (3) } R^{2}=1-\frac{\sum_{i=1}^{n}\left(y_{i}^{s}-y_{i}^{d}\right)^{2}}{\sum_{i=1}^{n}\left(y_{i}^{s}-\bar{y}\right)^{2}} \quad \text { where: } \overline{y^{\mathrm{s}}}=\sum_{i=1}^{n} y_{i}^{s}
$$

$y_{i}^{s}$ is the value of the emission spectrum of the standard measured at $i$-th wavelengths, $y_{i}^{d}$ is the value of the component spectrum at $i$-th wavelengths, $\mathrm{n}$ - number of measured fluorescence intensities at different emission wavelengths in spectra. If $\mathrm{R}=1$ then the component spectrum exactly corresponds to the emission spectra of the standard. To evaluate the total content of triglycerides, phospholipids and cholesterol we used equations:

$$
\begin{aligned}
& \text { (4) } \mathrm{TF}(\text { tri })=\mathrm{TF} \cdot \mathrm{MF}(\text { tri }), \mathrm{TF}(\mathrm{ph})=\mathrm{TF} \cdot \mathrm{MF}(\mathrm{ph}) \\
& \text { and } \mathrm{TF}(\text { chol })=\mathrm{TF} \cdot \mathrm{MF}(\mathrm{chol})
\end{aligned}
$$

because the content of triglycerides $\mathrm{TF}($ tri), phospholipids $\mathrm{TF}(\mathrm{ph})$ and cholesterol $\mathrm{TF}(\mathrm{chol})$ is a product of the total lipid content TF and appropriate multiplying factor of the component spec- 
trum $S_{P}(j)$. To simplify the later discussion we calculated relative values of $\mathrm{TF}(\operatorname{tri}), \mathrm{TF}(\mathrm{ph})$ and $\mathrm{TF}(\mathrm{chol})$. They were normalised by the mean value of TF obtained for BSA group $\overline{T F(B S A)}$ (and marked as $\mid \mathrm{TF}($ tri $)|,| \mathrm{TF}(\mathrm{ph}) \mid$ and $\mid \mathrm{TF}$ (chol)|:

(3) $|T F(t r i)|=\frac{T F(t r i)}{\overline{T F(B S A)}},|T F(p h)|=\frac{T F(p h)}{\overline{T F(B S A)}}$

and $\mid T F($ chol $) \mid=\frac{T F(\text { chol })}{\overline{T F(B S A)}}$.

One-dimensional ANOVA and a post hoc Tukey test were used to compare the content of triglycerides $\mathrm{TF}$ (tri), phospholipids $\mathrm{TF}(\mathrm{ph})$ and cholesterol TF(chol) calculated for different groups.

\section{Results}

Results of the in vitro survival of porcine zygotes cultured in NCSU-23 medium supplemented with BSA, FCS, BSA and PES, BSA and vitamin E or protein free NCSU23 are summarized in Table 1. Fluorescence spectra emitted from blastocysts stained with NR showed a maximum emission at $588 \mathrm{~nm}$ and ranged from $518 \mathrm{~nm}$ to $754 \mathrm{~nm}$. Therefore, morphological analysis of the blastocysts was carried out using images of the optical sections taken at $588 \mathrm{~nm}$ wavelength. For all analysed groups the morphology of the cultured blastocysts was the same and no developmental abnormalities were observed (Fig. 1). The Nile red fluorescence signal was mainly restricted to the ellipticalshaped lipid droplets distributed in the cytoplasm, whereas the cytoplasm and blastocyst cavity remained unstained.

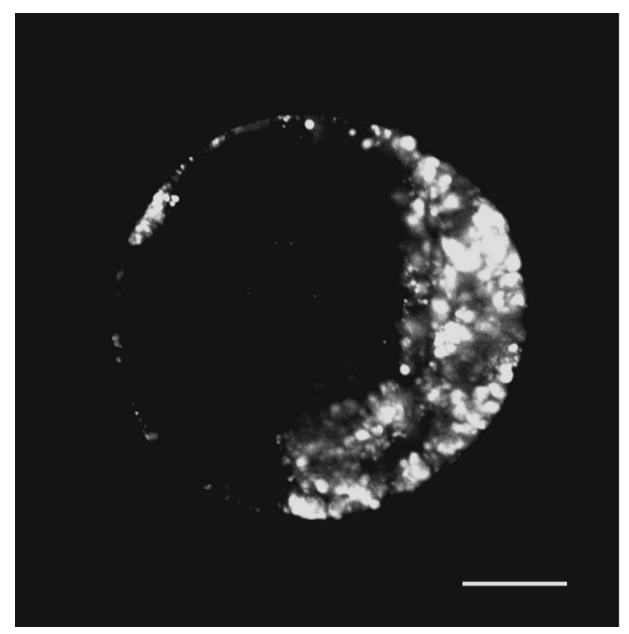

Table 1

In vitro survival of porcine zygotes cultured in NCSU-23 medium supplemented with BSA (BSA group), FCS (FCS group), without protein (control group - C), BSA and PES (PES group) or BSA and vitamin $\mathrm{E}$ (VE group)

\begin{tabular}{||l|c|c|}
\hline \hline & $\begin{array}{c}\text { No. of zygotes } \\
\text { cultured/replicates }\end{array}$ & $\begin{array}{c}\text { No. of expanded } \\
\text { blastocysts (\%) }\end{array}$ \\
\hline \hline BSA & $73 / 9$ & $59(80.8)$ \\
\hline FCS & $71 / 9$ & $20(28.2)$ \\
\hline C & $77 / 9$ & $17(22.1)$ \\
\hline PES & $98 / 7$ & $74(75.5)$ \\
\hline VE & $75 / 6$ & $60(80.6)$ \\
\hline
\end{tabular}

Each mean emission spectrum taken for all individual blastocysts always consists of the three component spectra $\mathrm{S}_{\mathrm{P}}(1), \mathrm{S}_{\mathrm{P}}(2)$ and $\mathrm{S}_{\mathrm{P}}(3)$ (Fig. 2). Multiplying factors of the component spectra: MF(1), MF(2) and MF(3) differed between the blastocysts and between the groups of embryos under study, but $\mathrm{S}_{\mathrm{P}}(1), \mathrm{S}_{\mathrm{P}}(2)$ and $\mathrm{S}_{\mathrm{P}}(3)$ did not change. Maxima of $S_{P}(1), S_{P}(2)$ and $S_{P}(3)$ were found at $588 \mathrm{~nm}, 631 \mathrm{~nm}$ and $641 \mathrm{~nm}$ respectively. Percent variance (PVC) of the PCA model was very high $(\mathrm{PVC}=99.93 \%)$.

Normalized emission spectra|tri|, $|\mathrm{ph}|$ and $\mid$ chol|, taken for three lipid standards and stained with NR, i.e. triglyceride mixtures, phospholipids mixture and cholesterol, respectively, are shown in Fig. 3. Their maxima occurred at $588 \mathrm{~nm}$ for |tri|, $631 \mathrm{~nm}$ for $|\mathrm{ph}|$ and $641 \mathrm{~nm}$ for $\mid$ chol|. They have not only the same maxima but also the same spec-

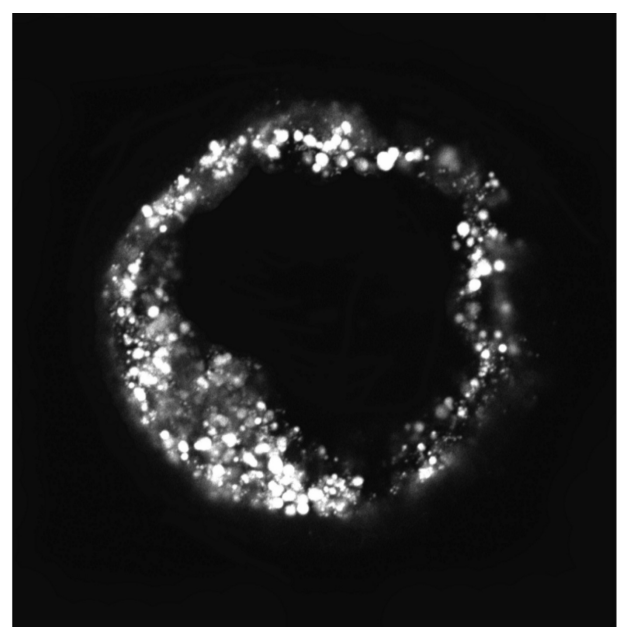

Fig. 1. Confocal images of the cultured blastocysts in NCSU-23 medium (left panel - BSA group) and in NCSU-23 medium supplemented with BSA and $0.05 \mu \mathrm{M}$ PES (right panel - PES group). Embryos were stained with NR and images were taken at $588 \mathrm{~nm}$ wavelength. Bar $=50 \mu \mathrm{m}$. 


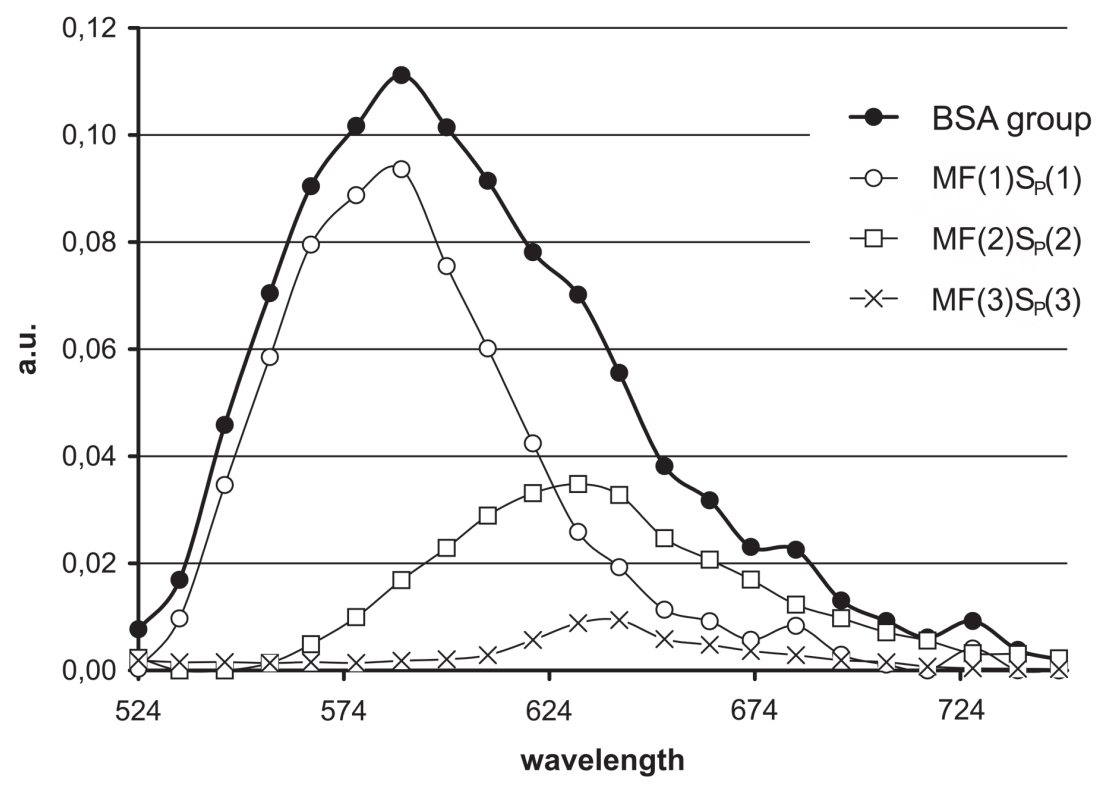

Fig. 2. Emission fluorescence spectrum of the porcine late-blastocyst stained with NR and cultured in NCSU-23 medium with BSA. It was deconvoluted into the three component spectra $\mathrm{S}_{\mathrm{p}}(1), \mathrm{S}_{\mathrm{p}}(2)$ and $\mathrm{S}_{\mathrm{p}}(3)$. Parameters $\mathrm{MF}(1), \mathrm{MF}(2)$ and $\mathrm{MF}(3)$ are multiplying factors of the appropriate component spectra in the experimental spectrum of blastocysts from the BSA group.

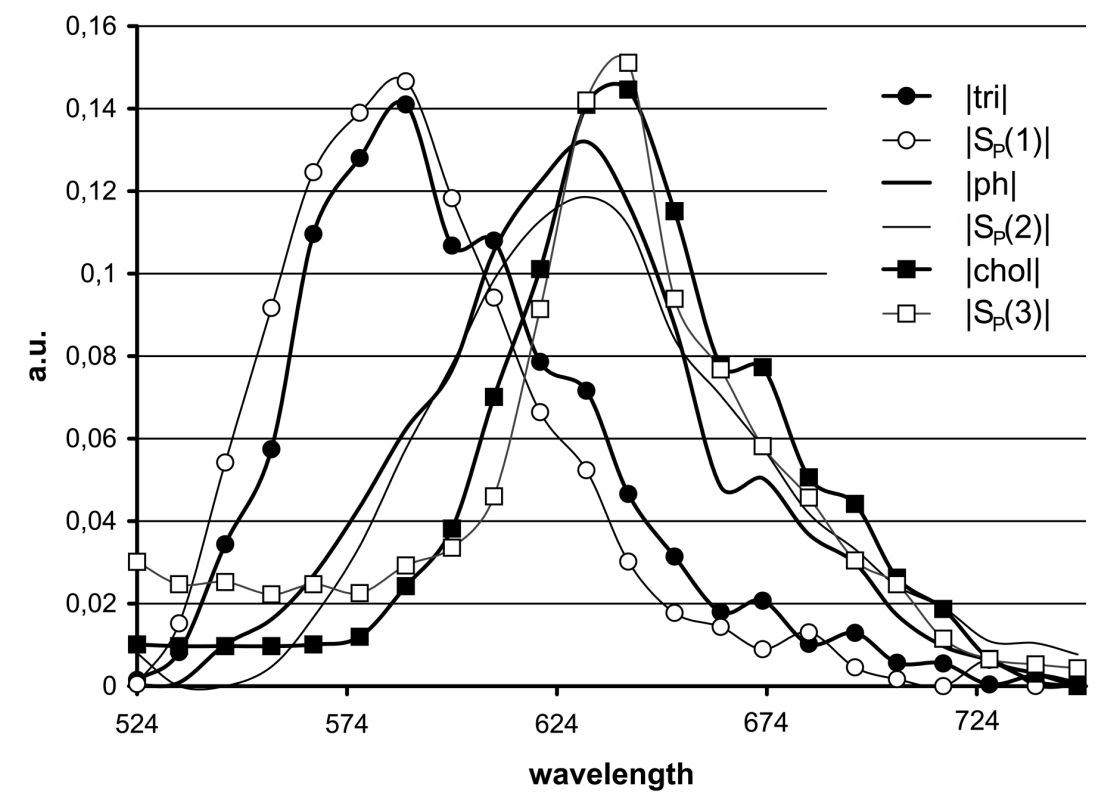

Fig. 3. Normalized component spectra $\left|S_{\mathrm{P}}(1)\right|,\left|\mathrm{S}_{\mathrm{P}}(2)\right|$ and $\left|\mathrm{S}_{\mathrm{P}}(3)\right|$ fit tight with the appropriate normalized emission spectra of triglycerides - |tri|, phospholipids - $|\mathrm{ph}|$ and cholesterol - |chol|, respectively. Spectra |tri|, |ph| and |chol| were taken for standard stained with NR.

trum profiles as appropriate component spectra $\mathrm{S}_{\mathrm{P}}(1), \mathrm{S}_{\mathrm{P}}(2)$ and $\mathrm{S}_{\mathrm{P}}(3)$ (Fig. 3). The quality of approximation is very high because the coefficient of determination $\mathrm{R}^{2}$ equals 0.922 for comparison $|\mathrm{s} 1|$ with $|\mathrm{s}(\operatorname{tri})|, 0.956$ for $|\mathrm{s} 2|$ with $|\mathrm{s}(\mathrm{ph})|$, and 0.927 for $|\mathrm{s}(\mathrm{chol})|$ with $|\mathrm{s} 3|$. Therefore, previously deconvoluted component spectra are responses of triglycerides, phospholipids and cholesterol stained with NR and contained in the lipid droplets of the studied blastocysts, whereas $\mathrm{MF}(1)=\mathrm{MF}($ tri $)$, $\mathrm{MF}(2)=\mathrm{MF}(\mathrm{ph})$ and $\mathrm{MF}(3)=\mathrm{MF}(\mathrm{chol})$ are multiplying factors (proportional to the percentage content) of appropriate types of lipids in samples.

Mean values of $\mid \mathrm{TF}$ (tri)|, |TF(ph)| and |TF(chol)| are shown in Table 2. Moreover, total lipid content $|\mathrm{TF}|$, which is a ratio of mean lipid content of the experimental group to the mean value calculated for the BSA group of blastocysts, is shown in Ta- 
Table 2

Normalized content of triglycerides $|\mathrm{TF}(\mathrm{tri})|$, phospholipids $|\mathrm{TF}(\mathrm{ph})|$ and cholesterol $|\mathrm{TF}(\mathrm{chol})|$ as well as normalized total lipid content $|\mathrm{TF}|$ estimated for different groups of blastocysts

\begin{tabular}{|l|c|c|c|c||}
\hline & $|\mathrm{TF}(\mathrm{tri})|{ }_{ \pm} \mathrm{SD}$ & $|\mathrm{TF}(\mathrm{ph})| \pm \mathrm{SD}$ & $|\mathrm{TF}(\mathrm{chol})| \pm \mathrm{SD}$ & $|\mathrm{TF}| \pm \mathrm{SD}$ \\
\hline \hline BSA & $0.636^{1-4}{ }_{ \pm} 0.061$ & $0.284 \pm 0.051$ & $0.071^{1-4}{ }_{ \pm} 0.018$ & $1^{1}{ }_{ \pm 0.106}$ \\
\hline FCS & $0.521^{1,5-7}{ }_{ \pm} 0.037$ & $0.262 \pm 0.061$ & $0.128^{1}{ }_{ \pm} 0.040$ & $0.914 \pm 0.090$ \\
\hline C & $0.476^{2,5,8}{ }_{ \pm} 0.017$ & $0.269_{ \pm} 0.020$ & $0.137^{2}{ }_{ \pm} 0.041$ & $0.881 \pm 0.121$ \\
\hline PES & $0.364^{3,6,8,9}{ }_{ \pm} 0.018$ & $0.228 \pm 0.040$ & $0.150^{3}{ }_{ \pm} 0.035$ & $0.740^{1}{ }_{ \pm} 0.125$ \\
\hline VE & $0.446^{4,7,9}{ }_{ \pm} 0.014$ & $0.261 \pm 0.035$ & $0.129^{4}{ }_{ \pm} 0.029$ & $0.828 \pm 0.100$ \\
\hline \hline F & 21.59 & 0.75 & 14.67 & 3.95 \\
\hline
\end{tabular}

BSA - group of blastocysts cultured in NCSU-23 medium with $4 \mathrm{mg} / \mathrm{mL}$ BSA, C - group of blastocysts cultured in NCSU-23 medium without BSA or FCS, FCS - group of blastocysts cultured in NCSU-23 medium with $4 \mathrm{mg} / \mathrm{mL}$ BSA and with: $10 \%$ FCS (FCS group), $0.05 \mu \mathrm{M}$ PES (PES group) or with $25 \mu \mathrm{M}$ vitamin E (VE group). ANOVA: F is the value of the F-distribution, $\mathrm{fl}=4$ and $\mathrm{f} 2=45$ are degrees of freedom among and within groups, confidence level $\mathrm{P}=0.05, \mathrm{SD}-$ standard deviation. The same superscript next to appropriate mean values in each column indicates statistically significant differences between different blastocyst groups under study. Notation 1-4 or 5-7 at superscript corresponds to $1,2,3,4$ or to $5,6,7$ respectively.

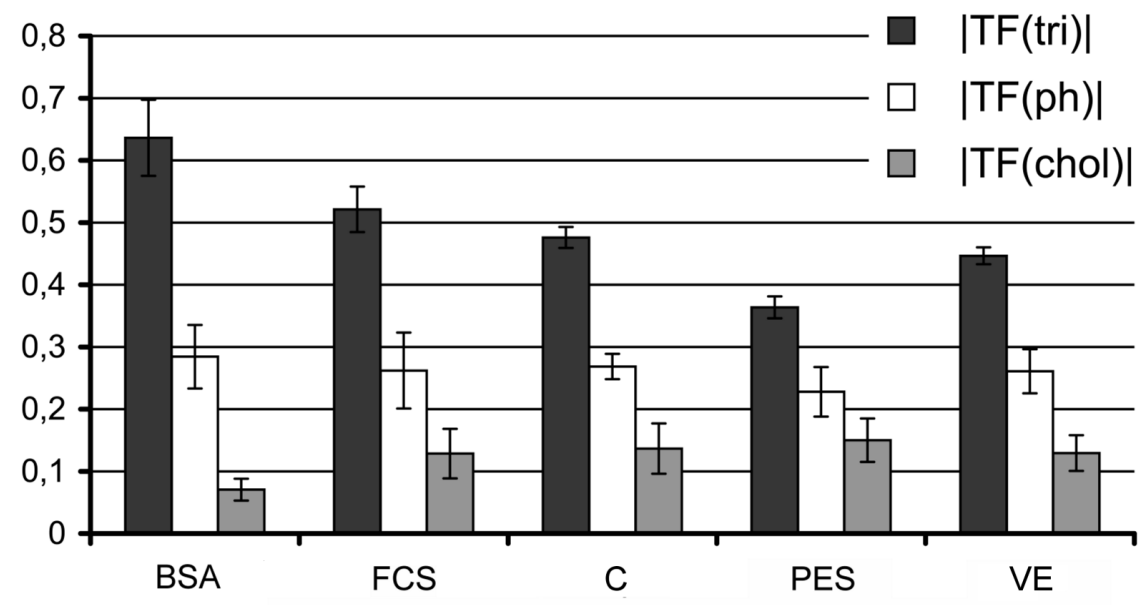

Fig. 4. Normalized values of the triglycerides - $\mid \mathrm{TF}($ tri) $) \mid$, phospholipids $-|\mathrm{TF}(\mathrm{ph})|$ and cholesterol $-\mid \mathrm{TF}$ (chol)| content for blastocysts cultured in: NCSU-23 medium with BSA (BSA group), without protein (C) and cultured in NCSU-23 medium with BSA and supplemented with: FCS (FCS group), PES (PES group) and vitamin E (VE). Parameters TF(tri), TF(ph) and $\mathrm{TF}(\mathrm{chol})$ were normalized by the mean value of the total lipid content estimated for BSA group $-\overline{T F(B S A)}$.

ble 2. The group of blastocysts cultured with addition of $0.05 \mu \mathrm{M}$ PES (PES group) had lower value of $|\mathrm{TF}|$ than that of the BSA group, but no other differences were found for total lipid content.

We found numerous statistically significant differences in content of triglycerides $\mid \mathrm{TF}($ tri) $\mid$ between blastocysts of different groups with high values of the F-distribution (Table 2 \& Fig. 4). Parameter $\mid \mathrm{TF}$ (tri) $\mid$ differs between all groups with one exception: no statistically significant difference was found between groups $\mathrm{C}$ and VE. With respect to the phospholipid content $|\mathrm{TF}(\mathrm{ph})|$, there are no significant differences between groups (Table 2 \& Fig. 4). Finally, the value of $|\mathrm{TF}(\mathrm{chol})|$ is significantly lower for the BSA group as compared to other groups.

\section{Discussion}

The lipid droplets of porcine oocytes and embryos contain mixtures of several lipid types, mainly triglycerides and phospholipids (MCEVOY et al. 2000). They show different degrees of polar- 
ity, therefore NR emission spectrum of stained blastocysts is a convolution of several principal spectra (MUKHERJEE et al. 2007; KĘPCZYŃSKI et al. 2008). The decomposition technique PCA/MCR-ALS suggested a three-component model. In consequence, we detected three types of lipids in lipid droplets of the analysed blastocysts. Their component spectra strictly corresponded to the fluorescence spectra measured for triglyceride, phospholipid and cholesterol standards. These findings are in good agreement with a qualitative, histochemical analysis of pig embryos (unpublished data). Moreover, multiplying factors of component spectra MF(tri), MF(ph) and MF(chol), calculated via the MCR-ALS method for each mean experimental spectrum are proportional to the percentage content of the three identified types of lipid in each individual blastocyst (TAULER 1995). It is important to mention that in the absence of a standard with a strictly defined amount of analysed lipid types placed in the same environment as the embryo cytoplasm, only the relative amount of lipids present in lipid droplets could be estimated by spectra decomposition and multiplying factor evaluation. Consequently, we analysed the content of triglycerides, phospholipids and cholesterol as well as the total lipid content for each studied blastocyst as a ratio to the mean total lipid content found for the BSA group. This scheme allows comparing the total lipid content and content of three classes of lipids in droplets between the different groups of analysed blastocysts.

Our results suggest that the culture system may modify triglyceride content in the porcine blastocysts (Fig. 4) but only PES supplementation leads to a statistically significant decrease in the total lipid content (Table 2). We observed a reduced amount of triglycerides in embryos cultured in medium supplemented with FCS, vitamin E and cultured in medium without protein in comparison to those cultured in this medium with BSA. It was previously shown that triglycerides are important sources of energy for early porcine embryos (TSUJII et al. 2001). Free fatty acids derived from triglycerides are metabolized through $\beta$-oxidation process in the mitochondrial matrix. Therefore, higher rate of embryo aerobic metabolism is a possible explanation of reduced triglyceride content in the analysed blastocysts. Surprisingly, FCS supplementation to culture medium did not result in lipid accumulation, especially triglycerides in porcine embryos, in contrast to bovine embryos (BARCELO-FIMBRES \& SEIDEL 2007; REIS et al. 2003). However, fetal calf serum has antioxidant properties, contains growth factors and numerous proteins which are responsible for transport of hormones, free fatty acids and $\mathrm{CO}_{2}$. Therefore FCS may stimulate aerobic metabolism as previously suggested (BAR-
CELO-FIMBRES \& SEIDEL 2007). Consequently we observed a small but statistically significant decrease of triglyceride content in FCS treated blastocysts. A similar explanation can be put forward for the lower triglyceride content in the blastocysts cultured in the presence of vitamin E. As was previously shown, vitamin E stimulates incorporation and oxidation of glucose at the blastocyst stage of mouse embryos (TSUJII et al. 2002). This supports the hypothesis that $\beta$-oxidation rates may be higher in the presence of vitamin $\mathrm{E}$ due to the fact that when free fatty acids are oxidized, small amounts of carbohydrates are required to provide oxaloacetate to prime the TCA cycle. In contrast, lipid accumulation may be the result of impaired $\beta$-oxidation due to abnormal mitochondrial activity (DORLAND et al. 1994) damaged by free radicals (TSUJII et al. 2002). Blastocysts cultured in medium without protein have lower triglyceride levels than those observed in the BSA group. The survival rate of such embryos is low because amino acids are beneficial for pig embryonic development (SWAIN et al. 2002). Amino acids are additional energy sources during preimplantation in pig development, however, Krebs cycle metabolism is higher for in vivo derived embryos than for in vitro cultured embryos (SWAIN et al. 2002). The authors speculate that the lipid metabolism rate may be higher in the absence of such additional energy sources.

Phenazine ethosulfate, a pharmacological regulator of embryo metabolism, was previously used for in vitro production of bovine (BARCELO-FIMBRES \& SEIDEL 2007; DE LA TORRE-SANCHEZ et al. 2006) and porcine embryos (GAJDA et al. 2008). The positive effect of PES on porcine embryo development was reflected in higher rates of cleaved embryos, morulae and blastocysts as well as low incidence of apoptosis in PES cultured embryos compared to those cultured without PES (GAJDA et al. 2008). Phenazine ethosulfate accepts $\mathrm{H}^{+}$ from NADPH, by converting NADPH ${ }^{+}$to $\mathrm{NADP}^{+}$, stimulates glucose metabolism via the pentose phosphate pathway and leads to decreased lipid production (DE LA TORRE-SANCHEZ et al. 2006; BARCELO-FIMBRES \& SEIDEL 2007). Accordingly, we observed reduced amounts of total lipid content and triglycerides in the PES-treated porcine blastocysts (GAJDA et al. 2008), although PES supplementation did not affect phospholipid and cholesterol content (Fig. 4).

We detected a significantly lower level of cholesterol only in the BSA group. Cholesterol is an important component of the molecular monolayer enclosing lipid droplets. Lower cholesterol content suggests that lipid droplets of blastocysts cultured in NCSU-23 medium with BSA have larger sizes and thus reduced area of the molecular mono- 
layer per unit volume of droplets. This effect was observed previously for bovine cultured embryos (BARCELO-FIMBRES \& SEIDEL 2007).

This is the first study in which triglyceride, phospholipid and cholesterol content has been examined in porcine blastocysts cultured in media of different composition. We inferred that porcine blastocysts cultured in NCSU-23 medium supplemented with FCS or BSA and PES or BSA and vitamin $\mathrm{E}$ have lower levels of triglycerides in comparison to those cultured in NCSU-23 with BSA only. In addition, embryos cultured in medium without protein also have lower triglyceride content compared to those cultured in medium supplemented with BSA. This may be explained by increased aerobic metabolism. Fetal calf serum supplementation of culture medium does not lead to lipid accumulation in porcine embryos at the blastocyst stage in contrast to bovine embryos.

\section{References}

BARCELO-FIMBRES M., SEIDEL Jr G. E. 2007. Effects of either glucose or fructose and metabolic regulators on bovine embryo. Development and lipid accumulation in vitro. Mol. Reprod. Dev. 74: 1406-1418.

DE LA Torre-Sanchez J. F., GARdNER D. K., PREIS K., GIBBONS J., SEIDEL Jr G. E. 2006. Metabolic regulation of in vitro-produced bovine embryos. II. Effects of phenazine ethosulphate, sodium azide and 2,4-dinitrophenol during post-compaction development on glucose metabolism and lipid accumulation. Reprod. Fertil. Dev. 18: 597-607.

DOBRINSKY J. R., JOHNSON L. A., RATH D. 1996. Development of a culture medium (BECM-3) for porcine embryos: effects of bovine serum albumin and fetal bovine serum on embryo development. Biol. Reprod. 55: 1069-1074.

DOBRINSKY J. R. 2002. Advancements in cryopreservation of domestic animal embryos. Theriogenology 57: 285-302.

Dorland M., Gardner D. K., TROUNSON A. O. 1994. Serum in SOF causes mitochondrial degeneration in ovine embryos. J. Reprod. Fertil. 13: 70.

GAJDA B., SMORAG Z. 2000. Survival of pig morula and blastocyst after exposure to vitrification media or vitrification. CryoLett. 21: 231-236.

GAJDA B., BRYŁA M., SMORĄG Z. 2008. Effects of protein source, vitamin $\mathrm{E}$ and phenazine ethosulphate on developmental competence and quality of porcine embryos cultured in vitro. Folia biol. (Kraków) 56: 57-63.

GENICOT G., LEROY J. L. M. R., VAN SOOM A., DONNAY I 2005. The use of a fluorescent dye, Nile red, to evaluate the lipid content of single mammalian oocytes. Theriogenology 63: $1181-1194$

KĘPCZYŃSKI M., NAWALANY K., KUMOREK M., KOBIERSKA A., JACHIMSKA B., NOWAKOWSKA M. 2008. Which physical and structural factors of liposome carriers control their drug-loading efficiency? Chem. Phys. Lipids 155: 7-15.

KURGANOV B. I., LOBANOV A. V., BORISOV I. A., RESHETILOV A. N. 2001. Criterion for Hill equation validity for description of biosensor calibration curves. Anal. Chim. Acta 427: $11-19$.
LEROY J. L. M. R., GENICOT G., DONNAY I., VAN SOOM A. 2005. Evaluation of the lipid content in bovine oocytes and embryos with Nile red: A practical approach. Reprod. Dom. Anim. 40: 76-78.

McEvoy T. G., COULl G. D., BROADBENT P. J., HUTCHINSON J. S. M., SPEAKE B. K. 2000. Fatty acid composition of lipids in immature cattle, pig and sheep oocytes with intact zona pellucida. J. Reprod. Fertil. 118: 163-170.

McEvoy T. G., Robinson J. J., SinclaiR K. D. 2001. Developmental consequences of embryo and cell manipulation in mice and farm animals. Reproduction 122: 507-518.

MukHERJEe S., Raghuraman H., Chattopadhyay A. 2007. Membrane localization and dynamics of Nile Red: effect of cholesterol. Biochim. Biophys. Acta 1768: 59-66.

NAGASHIMA H., KASHIWAZAKI N., ASHMAN R. J., GRUPEN C. G., SEAMARK R. F., NOTTLE M. B. 1994. Removal of cytoplasmic lipid enhances the tolerance of porcine embryos to chilling. Biol. Reprod. 51: 618-622.

PALASZ A. T., RODRIGUEZ-MARTINEZ H., BELTRAN-BRENA P., PEREZ-GARNELO S., MARTINEZM. F., GUTIERREZ-ADAN A., DE LA FUENTE J. 2006. The effect of hyaluronan, BSA and serum on bovine embryo in vitro development, ultrastructure and gene expression patterns. Mol. Reprod. Dev. 73: 1503-1511

Palasz A. T., Beltran-Brena P., Martinez M. F., PEREZ-GARNELO S. S., RAMIREZ M. A., GUTIERREZ-ADAN A., DE LA FUENTE J. 2008. Development, molecular composition and freeze tolerance of bovine embryos cultured in TCM-199 supplemented with hyaluronan. Zygote 16: 39-47.

PEREIRA R. M., MARQUES C. C. 2008. Animal oocyte and embryo cryopreservation. Cell Tiss. Bank, doi:10.1007/s10561008-9075-2. Published online 22 May.

RATH D., NIEMANN H., TORRES C. R. L. 1995. In vitro development to blastocyst of early porcine embryos produced in vitro or in vivo. Theriogenology 43: 913-926.

Reis A., Rooke J. A., McCallum G. J., Staines M. E., EWEN M., LOMAX M.A., MCEVOY T. G. 2003. Consequences of exposure to serum, with or without vitamin $\mathrm{E}$ supplementation, in terms of the fatty acids content and viability of bovine blastocysts produced in vitro. Reprod. Fertil. Dev. 15: 275-284.

RomeK M., GAJdA B., KrZYSZTOFowicz E., SMORĄG Z. 2009. Lipid content of non-cultured and cultured pig embryo. Reprod. Domest. Anim. 44: 24-32

SEIDEL Jr G. E. 2006. Modifying oocytes and embryos to improve their cryopreservation. Theriogenology $65: 228-235$.

SWAIN J. E., BORMANN C. L., Clark S. G., WALTERS E. M., WHEELER M. B., KRISHER R. L. 2002. Use of energy substrates by various stage preimplantation pig embryos produced in vivo and in vitro. Reproduction 123: 253-260.

TAULER R. 1995. Multivariate curve resolution applied to second order data. Chemom. Intell. Lab. Sys. 30: 133-46.

Teixeira A. P., Oliveira R., Alves P. M., CARrondo M. J. T. 2009. Advances in on-line monitoring and control of mammalian cell cultures: Supporting the PAT initiative. Biotech. Adv. 27: 726-732.

TSUJII H., MURANAKA M., HAMANO K. 2002. Culture of in vitro mouse embryos with vitamin $\mathrm{E}$ improves development. J. Reprod. Dev. 48: 25-29.

TsujiI H., Khandoker M. A. M. Y., Hamano K. 2001. Lipid in mammalian embryo development. J. Mamm. Ova Res. 18: 73-80.

VAJTA G., NAGY Z. P. 2006. Are programmable freezers still needed in the embryo laboratory? Review on vitrification. Reprod. Biomed. Online 12: 779-796.

Yoneda A., Suzuki K., Mori T., Ueda J., Watanabe T. 2004. Effect of delipidation and oxygen concentration on in vitro development of porcine embryos. J. Reprod. Dev. 50: 287-295. 